\title{
Gestational age, mode of delivery, and relation to the day and time of birth in two private health care facilities
}

\author{
Ramón Larcade, M.D. ${ }^{a}$, Norma Rossato, M.D. ${ }^{b}$, Christian Bellecci, M.D. ${ }^{a}$, \\ Ariel Fernández, Magister ${ }^{c}$, Cecilia García, M.D. ${ }^{b}$ and Néstor Vain, M.D. ${ }^{a, b, c}$ \\ Collaborators: Ivana Liz Ruano and Lucía Segovia
}

\begin{abstract}
Introduction. There is a worldwide growing trend of preterm births and C-sections. Our objective was to describe gestational age (GA), mode of delivery, day and time distribution, and the relation between the mode of delivery and the time of birth in two private facilities.

Population and methods. Prospective, crosssectional, analytical study.

Results. A total of 1500 livenewborn infants were included between September 2017 and August 2018 (1465 pregnant women). Of these, $99.4 \%$ had received antenatal care; $66.8 \%$ of pregnancies ended via C-section. The reason was a previous C-section in $36.4 \%$, lack of progression and descent in $18.9 \%$, and maternal choice in $9.2 \%$. The average birth weight was $3232 \mathrm{~g} \pm 561.1 \mathrm{~g}$ and the median GA was 39 weeks (range: $38-40$ ) based on the date of the last menstrual period; $88.2 \%$ were term births and, among preterm births, $76.1 \%$ corresponded to late preterm babies. Early term births showed a higher rate of C-sections $(p<0.001)$. There were 849/1201 $(74.5 \%$ ) C-sections on weekdays and 173/299 $(57.9 \%, p<0.001)$ on weekends and holidays. A statistically significant relation was observed between the time of birth and the performance of a C-section.

Conclusions. The median GA was 39 weeks. C-sections were the most common mode of delivery. Births occurred predominantly Mondays through Fridays between 8 a.m. and 9 p.m.; $82.9 \%$ of C-sections took place on weekdays.

Key words: gestational age, delivery, C-section, preterm newborn infant, epidemiology.
\end{abstract}

http: / / dx.doi.org/10.5546/ aap.2021.eng.18

To cite: Larcade R, Rossato N, Bellecci C, Fernández A, et al. Gestational age, mode of delivery, and relation to the day and time of birth in two private health care facilities. Arch Argent Pediatr 2021;119(1):18-24.

E-mail address:

Ramón Larcade, M.D. ramonlarcade@gmail. com

Funding:

None.

Conflict of interest:

None.

Received: 6-8-2020

Accepted: 7-20-2020

\section{INTRODUCTION}

Disorders related to the length of gestation and fetal growth are some of the main causes of neonatal morbidity and mortality. ${ }^{1,2}$ Worldwide, there is a growing trend of preterm births. Each year, approximately 15 million preterm infants are born, and 1 million die due to prematurityrelated disorders, which are the main cause of infant mortality and the second leading cause among children younger than 5 years.,

In Argentina, there were 685394 live births (LBs) in 2018; 8.8\% of them were preterm infants. These have a higher risk for short- and long-term complications, including respiratory problems, retinopathy of prematurity, neurodevelopmental disorders, and cerebral palsy.5,6

C-section births are also increasing worldwide. The greater neonatal morbidity associated with $\mathrm{C}$-sections may be significantly reduced if performed after 39 weeks of gestation. ${ }^{7-10}$ The selected mode of delivery may be related to nonmedical reasons and have an impact on maternal and neonatal morbidity and mortality. ${ }^{11}$

In Argentina, in the private health care subsector, there are no recently published data about the mode of delivery, although it is known, through personal communications, that C-sections are more common.9-12 Knowing the current frequency and the main reasons for $\mathrm{C}$-sections would allow to design health care protocols in accordance with such high rate. ${ }^{13,14}$ Our objective was to describe gestational age (GA), mode of delivery, day and time distribution, and the relation between the mode 
of delivery and the time of birth in two private facilities.

\section{POPULATION AND METHODS}

This was a prospective, cross-sectional, analytical study. Participating sites were two private facilities from the Metropolitan Area of Buenos Aires that catered mostly for a population with private health insurance coverage with an annual average of 2000 deliveries at that moment. Considering the representativity of births for each day of the week and the study feasibility, participants were selected by convenience and the sample size was established at 1500 newborn infants (NBIs) between both facilities. All live NBIs born with a birth weight $\geq 500 \mathrm{~g}$ in the study period were selected consecutively.

The information was collected prospectively from maternal and neonatal medical records (patient charts, fetal ultrasounds). An ad hoc form included in an electronic database was used, and data were anonymized.

\section{Outcome measures}

Pregnancy-related: maternal age, obstetric history, and any pathology occurred in the last pregnancy. Adequate antenatal care was defined as a pregnancy with $\geq 5$ antenatal care visits as of the first trimester.

NBI-related: weight in grams, GA in weeks, mode of delivery (vaginal or $\mathrm{C}$-section and reason based on obstetric medical record). GA was established based on three methods: date of last menstrual period (LMP), GA as recorded by the obstetric team in the maternal medical record, and early ultrasound (up to 20 weeks of gestation). Results were estimated using GA based on the date of the LMP, if available. ${ }^{15}$

Term NBIs were defined as those born at a GA of $37-41^{+6}$ weeks; early term NBIs, as those born at a GA of $37-38^{+6}$ weeks; and full-term NBIs, as those born at a GA of $39-41^{+6}$ weeks. Preterm NBIs were defined as those born at a GA of $22-36^{+6}$ weeks and late preterm NBIs, as those born between 34 and $36^{+6}$ weeks. ${ }^{16}$

The moment of birth was recorded as date, day of the week, time of birth, and number of days until the following holiday based on the hypothesis that it may be a reason for an increased number of births by obstetric decision not related to maternal or fetal conditions.

\section{Ethical aspects}

This protocol and the data collection form were approved by the Ethics Committees and the Teaching Committees of Clinical Research and Medical Education Center "Norberto Quirno" (Centro de Educación Médica e Investigaciones Clínicas, CEMIC) and Universidad Austral.

\section{Statistical analysis}

The Stata ${ }^{\circledR}$ software, version 11 , was used. Descriptive statistics were established; continuous outcome measures were described as mean and standard deviation (SD), whereas categorical outcome measures, as frequency and percentage.

Student's t test was used to compare continuous outcome measures, and the $\chi^{2}$ test, to compare categorical outcome measures. A value of $p<0.05$ was considered statistically significant. The strength of the association was described using the odds ratio (OR) and the $95 \%$ confidence interval (CI). A multivariate logistic regression analysis was done to assess the factors associated with the indication for a C-section.

\section{RESULTS}

Data were collected at Sanatorio de la Trinidad Palermo between September 2017 and January 2018, and at Sanatorio de la Trinidad Ramos Mejía between May and August 2018. The study period at each site depended on the availability of the leading investigator to ensure recording continuity.

TABLE 1. Maternal data (N: 1465)

\begin{tabular}{lc}
\hline Maternal data & N (\%) \\
\hline Maternal age (years), mean \pm SD & $32.7 \pm 5.25$ \\
Gravidity & \\
1 & $622(42.5)$ \\
$\geq 2$ & $843(57.5)$ \\
Antenatal care & $1457(99.4)$ \\
Early ultrasound & $1414 / 1465(96.5)$ \\
GA (weeks), mean \pm SD & $7.7 \pm 2.1$ \\
Known date of LMP & $1347 / 1465(91.9)$ \\
Mode of delivery & \\
Vaginal & $486 / 1465(33.2)$ \\
$\quad$ Singleton & 484 \\
$\quad$ Twins & 2 \\
C-section & $979 / 1465(66.8)$ \\
$\quad$ Singleton & 944 \\
$\quad$ Twins & $34(1$ stillborn) \\
Previous C-section & 1 (only 1 NB included) \\
1 previous C-section & $454 / 1465(31.0)$ \\
$\geq 2$ & $375 / 1465(25.6)$ \\
\hline
\end{tabular}

SD: standard deviation; LMP: last menstrual period; GA: gestational age; NBI: newborn infant. 
During the study period, 1465 pregnant women were admitted; 1428 had a singleton pregnancy; 36, a twin pregnancy (in one case, 1 stillborn); and 1, a triplet pregnancy, for which only the first NBI was included because the estimated sample size had been reached. All 1500 live NBIs were included in the study.

\section{Pregnancy description}

A total of 1465 pregnancies were analyzed (Table 1). In 144/1465 (9.8\%), labor was induced; $86 / 144(59.7 \%)$ corresponded to C-sections, and $58 / 144(40.3 \%)$, to a vaginal delivery.

In addition to fetal-maternal indications, the reasons for a $\mathrm{C}$-section included prior $\mathrm{C}$-section (n: 356/979; 36.4\%), lack of progression and descent (n: 185/979; $18.9 \%$ ), and maternal choice (n: $90 / 979 ; 9.2 \%$ ). Table 2 shows the factors independently associated with the performance of a C-section in the multivariate analysis.

Among the 622 primiparous women, 407 $(65.4 \%)$ had a C-section. The reason mentioned for this was lack of progression and descent in $133(32.7 \%)$ and maternal choice in $50(12.3 \%)$.

\section{Description of newborn infants}

The average birth weight was $3232 \mathrm{~g}$ $(\mathrm{SD} \pm 561.1 \mathrm{~g})$. The median GA was 38 weeks (interquartile range [IQR]: 37-39) based on early ultrasound and 39 weeks (IQR: 38-40) based on the date of the LMP.

\section{Term and preterm newborn infants}

Among 1500 NBIs, 1324 (88.3\%) were term infants and $176(11.7 \%)$, preterm babies. Among term NBIs, $592(44.7 \%)$ corresponded to early term babies. In this group, C-sections (74.5\% versus $59.4 \%$ ) and $C$-section due to prior C-section (32.4\% versus $19.3 \%$ ) were more common than in the full-term NBI group.

Among preterm NBIs, $134(76.1 \%)$ were late preterm babies. In the group of late preterm NBIs plus early term NBIs (726), C-section deliveries were more common (546) compared to NBIs born $\geq 39$ weeks (435) $(75.2 \%$ versus $59.4 \%$; OR: 2.1; 1.64-2.6; $p<0.001)$.

\section{Day and mode of delivery}

The study period lasted 245 days. A total of 1201 babies were born on weekdays (not

TABLE 2. Factors associated with C-section performance. Multivariate analysis

\begin{tabular}{lccc}
\hline Outcome measures & Odds ratio & $\mathbf{9 5 \%} \mathbf{C I}$ & $p$ value \\
\hline Previous C-section & 12.7 & $8.46-19.08$ & 0.000 \\
Previous abortion/miscarriage & 1.58 & $1.1-2.27$ & 0.013 \\
Multiple pregnancy & 11.74 & $4.04-34.12$ & 0.000 \\
Macrosomia & 15.09 & $3.54-64.18$ & 0.000 \\
IUGR & 6 & $1.73-20.79$ & 0.005 \\
Oligohydramnios-polyhydramnios & 5.65 & $1.96-16.28$ & 0.001 \\
Pregnancy-induced HTN & 4.8 & $2.1-11.08$ & 0.000 \\
Daytime & 5.11 & $3.38-7.75$ & 0.000 \\
\hline
\end{tabular}

IUGR: intrauterine growth restriction; HTN: arterial hypertension; CI: confidence interval.

TABLE 3. Distribution of newborn infants by day of the week and relation to holidays

\begin{tabular}{lccc}
\hline Day of the week & $\begin{array}{c}\text { Newborn infants } \\
\mathbf{N}(\%)\end{array}$ & Vaginal delivery & C-section \\
\hline Mondays through Thursdays, not on the eve & $916(61.1)$ & $271(55.53)$ & $645(63.74)$ \\
of a holiday (128 days) & $7.1 /$ day & & $194(19.17)$ \\
Fridays and on the eve of a holiday (37 days) & $285(19.0)$ & $91(18.64)$ & $173(17.09)$ \\
Saturdays, Sundays, holidays (80 days) & $7.7 /$ day & $126(25.82)$ & $1012(100.00)$ \\
\hline Total & $299(19.9)$ & $488(100.00)$ & \\
\hline
\end{tabular}


a holiday) (7.3/ day) and 299, on Saturdays, Sundays or holidays (3.7/ day) (Table 3). The rate of C-sections on business days was $69.85 \%$ and on Saturdays, Sundays or holidays, $57.85 \%$ (OR: $1.67 ; 1.27-2.18 ; p<0.001)$ (Figure 1).

\section{Time of birth and mode of delivery}

Between 10:00 p.m. and 8:00 a.m., vaginal deliveries prevailed $(174 / 289 ; 60.2 \%)$; as of 08:00 a.m., the number of C-sections increased and remained high until 10:00 p.m. (897/1211; $74.1 \%$ of C-sections) (Figure 2). Considering the
12:00 a.m. to 05:00 a.m. time slot, a statistically significant relation was observed between the time of birth and the performance of a C-section as a delivery mode (Table 4 ).

\section{DISCUSSION}

During the study period, $66.8 \%$ of births corresponded to $\mathrm{C}$-sections, and the main reasons for it included prior C-section $(36.4 \%)$, lack of progression and descent $(18.9 \%)$, and maternal choice $(9.2 \%)$. The proportion of C-sections has increased in the past 35 years, especially those

FIGURE 1. Number of newborn infants by day of the week and mode of delivery

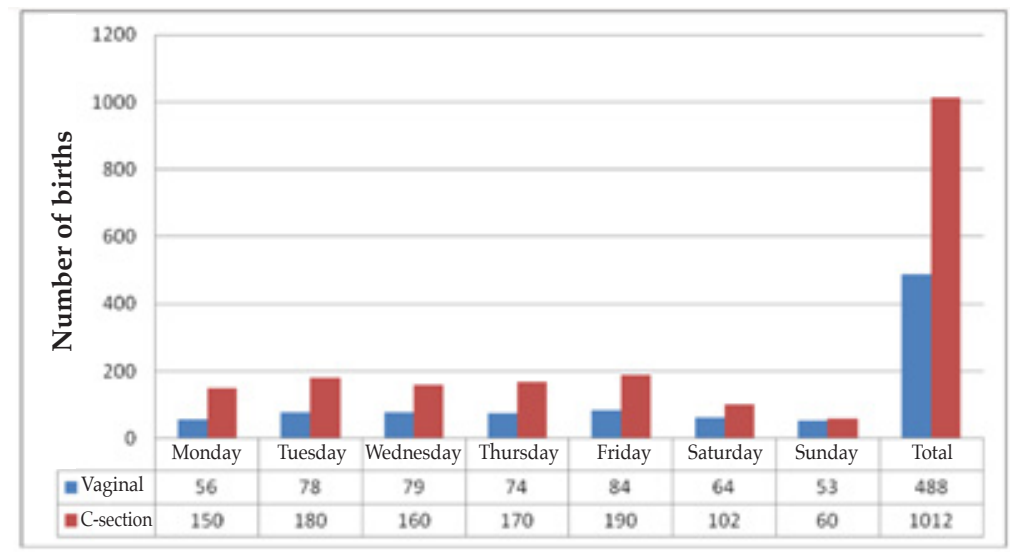

FIGURE 2. Time of birth and mode of delivery of newborn infants

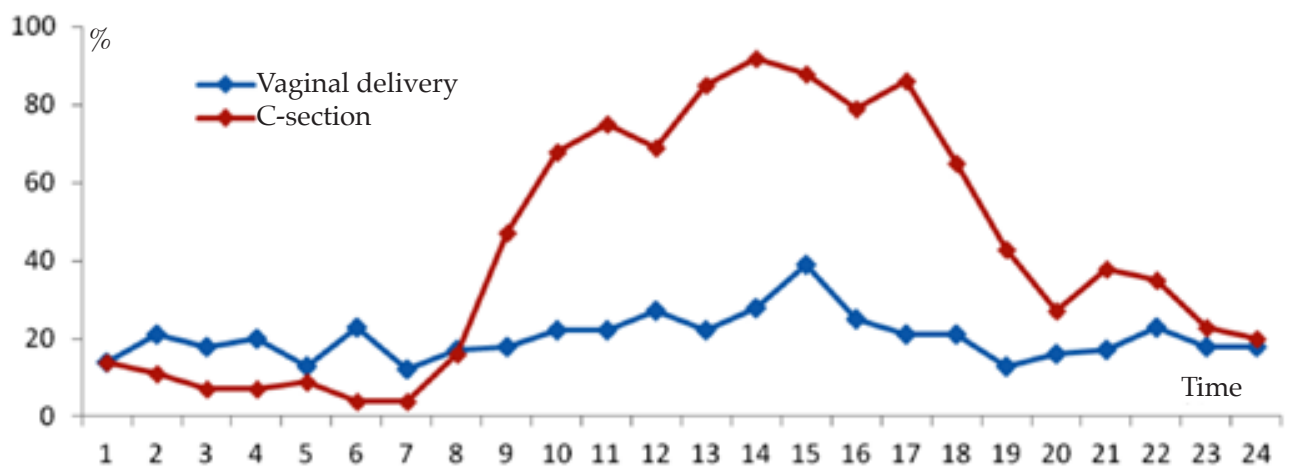

TABLE 4. Relation between time and mode of delivery

\begin{tabular}{lcccc}
\hline Time slot & Births & Vaginal delivery & C-section & OR for C-sections (95\% CI) \\
\hline 0:00 a.m.-5:59 a.m. & 161 & $\mathbf{1 0 9 ( 6 7 . 7 )}$ & $\mathbf{5 2 ( 3 2 . 3 )}$ & $\mathbf{1}$ \\
6:00 a.m.-11:59 a.m. & 397 & $118(29.72)$ & $279(70.28)$ & $4.96(3.34-7.35)$ \\
12:00 p.m.-5:59 p.m. & 651 & $156(23.96)$ & $495(76.04)$ & $6.6(4.57-9.71)$ \\
6:00 p.m.-11:59 p.m. & 291 & $105(36.08)$ & $186(63.92)$ & $3.7(2.47-5.61)$ \\
\hline
\end{tabular}

OR: odds ratio; CI: confidence interval. 
that cannot be justified by complications or maternal and fetal risks. ${ }^{19}$

In Latin America and the Caribbean, the average rate of C-sections is approximately $42 \%$ and, in some countries, it even reaches $70 \%$ or more. ${ }^{17}$ In some private health care centers of Brazil, the rate of $\mathrm{C}$-sections is even close to $90 \% .^{18}$ In Argentina, the rate of C-sections has also increased in recent years. ${ }^{19}$ Two private health care centers from Buenos Aires reported that, between 2004 and 2007, the frequency of C-sections among term NBIs was close to $50 \% .{ }^{9,12}$ Such frequency and that observed in our cohort far exceed that reported in the public sector. ${ }^{19}$

In our country, there is no accurate or recent information about the proportion of C-sections out of all births in the private setting. Health care centers should have statistics based on the SIP (for the acronym of Sistema Informático Perinatal) or any other database and it would be advisable to have public health regulations in place that made reporting such data mandatory..$^{20}$ Many cultural, social, and health care system factors may influence the difference in the incidence of $\mathrm{C}$-sections between the public and private sectors, as well as patients' demand for customized care, low compensations, and obstetric litigation, among many others.

The diagnoses recorded as a reason for $\mathrm{C}$-section in our study are partly similar to those published by Barber et al., who reported that the main reasons for a primary $\mathrm{C}$-section were lack of progression and descent, altered fetal vital signs, and malpresentation, among others. ${ }^{21}$ The indications for C-section reported in our cohort differ from those suggested by the World Health Organization (WHO). ${ }^{22}$

Currently, a vaginal birth after C-section is highly uncommon. ${ }^{14,23}$ The high rate of C-sections among nulliparous women is what possibly leads these women to have a higher number of $\mathrm{C}$-sections. The indication for a C-section due to a prior C-section is controversial. Pregnant women should be informed about the potential benefits of a vaginal delivery as long as maternal-fetal conditions warrant it. ${ }^{24}$

In our study, in the general sample, $9.2 \%$ of C-sections were a maternal choice $(12.3 \%$ among nulliparous women). Regarding the mode of delivery, in recent years, the medical community has witnessed a social and cultural change in relation to women empowerment in different areas and aspects, from deciding the right time to become a mother to selecting the reproductive method and the number of children they want.
For an informed decision-making, it is very important that pregnant women and their partners know and understand the risks and benefits of selecting this mode of delivery when they have a low risk pregnancy, both in terms of potential impact for the mother and the baby and the relation to the moment selected for the surgery. This is a critical aspect that requires the involvement of the health care team. ${ }^{17}$

A statistically significant difference was observed in the rate of $\mathrm{C}$-sections between early term and full-term NBIs. This is consistent with the increase in deliveries after induced labor and $\mathrm{C}$-sections observed in recent years. Different studies have shown that the population of early term NBIs have a higher neonatal morbidity compared to those born between 39 and 41 weeks. ${ }^{25-28}$

These results are consistent with those observed by Martínez-Nadal et al., who found a significantly higher rate of $\mathrm{C}$-sections among early term NBIs and a higher proportion of admission to the neonatal intensive care unit and morbidity in general compared to those born at 39-41 weeks of gestation. ${ }^{28}$ Hourani et al., observed more respiratory morbidity, hypothermia, and feeding difficulties among early term NBIs than among those born at 39 or more weeks of gestation. ${ }^{11}$

Worldwide, there is a growing trend of preterm births. ${ }^{7,8,29,30}$ In our study, $11.7 \%$ of NBIs were born preterm. Such rates exceed those reported in national data $(8.8 \%$ of preterm births), obtained mostly from public hospital records. ${ }^{5}$ The fact that reporting is not mandatory and that there is no unified recording form for the private subsector leads to not having reliable data available. Our study did not assess neonatal morbidity because the small sample size prevented us from drawing valid conclusions. However, it is known that a higher morbidity is associated with prematurity. ${ }^{8}$

In our study, late preterm NBIs accounted for $76 \%$ of preterm births. This is consistent with international publications. ${ }^{6,30}$ The importance of knowing their incidence is "to make them visible" because many times this group is underestimated by the health care team, who wrongly assume that they are "almost" term NBIs. These infants are associated with higher levels of morbidity and mortality, including respiratory distress, hypoglycemia, temperature regulation disorders, suction-swallowing disorders, hyperbilirubinemia, increased susceptibility to infections, and readmissions. 
In the long term, they may also have a poorer academic performance (reading, writing, and math skills). ${ }^{30-34}$

Mondays through Fridays, C-sections were 2-3 times more common than vaginal deliveries. However, on Sundays, the frequency of births was lower and the number of vaginal deliveries and C-sections was very similar. Most likely, such difference is related to the fact that elective C-sections are scheduled on weekdays for the convenience of the family or the obstetric team.

These results are similar to those observed by Del Carmen et al., who assessed the relation between the day of the week and the mode of delivery. Those authors found that women had a $25-29 \%$ lower chance of having a C-section on weekends and holidays compared to weekdays. ${ }^{35}$ In the same line, Young et al. described a phenomenon called the "weekend effect," during which the number of births and the percentage of C-sections are lower compared to weekdays. ${ }^{36}$

In relation to the time of birth, it was observed that births increased progressively between 7:00 a.m. and 2:00 p.m. and remained high until 9:00 p.m. Consistent with this, C-sections also increased as of 8:00 a.m. and remained high until 10:00 p.m. It is very worth noting that, between 9:00 a.m. and 6:00 p.m.; C-sections doubled and, at times, tripled the number of vaginal deliveries.

Nam et al. and Pasupathy et al., among others, described, in observational studies, a worse prognosis among the mothers and NBIs cared for during week nights or weekends and holidays compared to day shifts or weekdays. However, Brookfield et al., did not find a significant association in severe neonatal morbidity between studied groups (NBIs born during the day shift, the night shift or the early morning shift). ${ }^{37-39}$

In our study, the analysis of the time of birth and its proximity to the weekend or a holiday showed that $19 \%$ of births took place on Fridays or on the eve of a holiday. This was consistent with the report by Mola et al., about a higher frequency of births and late preterm NBI admission to the neonatology unit on Fridays. Those authors called it "the Friday effect". ${ }^{40}$

The information resulting from this study suggests that births took place on a day and at a time more likely related to the decisions of the medical team and/or the family rather than to maternal or fetal health reasons. Based on multiple personal communications, it is known that this is a common situation in many private health care centers of our country.
These data may be useful for facilities facing similar problems organizing human resource distribution and delivery and hospitalization area optimization. It would also be beneficial to implement mandatory, official reporting of similar information by all private facilities where births take place in order to design care strategies or health policies aimed at addressing the problem of such high rate of $\mathrm{C}$-sections.

\section{CONCLUSIONS}

The median GA was 39 weeks. C-sections were the most common mode of delivery. Births occurred predominantly Mondays through Fridays between 8 a.m. and 9 p.m. Also, $82.9 \%$ of C-sections took place on weekdays.

\section{REFERENCES}

1. Finkelstein JZ, Duhau M, Fasola ML, Escobar P. Mortalidad neonatal en Argentina. Análisis de situación de 2005 a 2014. Arch Argent Pediatr. 2017; 115(4):343-9.

2. Lona Reyes JC, Pérez Ramírez RO, Llamas Ramos L, Gómez Ruiz LM, et al. Mortalidad neonatal y factores asociados en recién nacidos internados en una Unidad de Cuidados Neonatales. Arch Argent Pediatr. 2018; 116(1):42-8.

3. Howson CP, Kinney MV, Lawn JE (eds.). Born Too Soon: The Global Action Report on Preterm Birth. Geneva: March of Dimes, PMNCH, Save the Children, WHO; 2012.

4. Beck S, Wojdyla D, Say L, Betran AP, et al. The worldwide incidence of preterm birth: a systematic review of maternal mortality and morbidity. Bull World Health Organ. 2010; 88(1):31-8.

5. Dirección de estadísticas e información en salud. Indicadores básicos. Argentina. 2018. [Accessed on: April $\left.20^{\text {th }}, 2020\right]$. Available at: http: / / www.deis.msal.gov.ar/ wp-content/ uploads/2019/02/Indicadores-Basicos-2018. pdf.

6. Delnord M, Zeitlin J. Epidemiology of late preterm and early term births - An international perspective. Semin Fetal Neonatal Med. 2019; 24(1):3-10.

7. Spong CY, Mercer BM, D'alton M, Kilpatrick S, et al. Timing of indicated late-preterm and early-term birth. Obstet Gynecol. 2011; 118(2 Pt 1):323-33.

8. PurischSE, Gyamfi-Bannerman C. Epidemiology of preterm birth. Semin Perinatol. 2017; 41(7):387-91.

9. Ceriani Cernadas JM, Mariani G, Pardo A, Aguirre A, et al. Nacimiento por cesárea al término en embarazos de bajo riesgo: efectos sobre la morbilidad neonatal. Arch Argent Pediatr. 2010; 108(1):17-23.

10. Reddy UM, Ko CW, Raju TNK, Willinger M. Delivery indications at late-preterm gestations and infant mortality rates in the United States. Pediatrics. 2009; 124(1):234-40.

11. Hourani M, Ziade F, Rajab M. Timing of planned caesarean section and the morbidities of the newborn. $N$ Am J Med Sci. 2011; 3(10):465-8.

12. Armadans M, Osorio MF, Pedicone C, Durán P, et al. Morbilidad en recién nacidos de término en relación a su edad gestacional. Rev Chil Pediatr. 2010; 81(5):402-8.

13. Zanardo V, Simbi AK, Franzoi M, Soldà G, et al. Neonatal respiratory morbidity risk and mode of delivery at term: influence of timing of elective caesarean delivery. Acta Paediatr. 2004; 93(5):643-7.

14. American College of Obstetricians and Gynecologists; 
Society for Maternal-Fetal Medicine; Caughey AB, Cahill AG, et al. Safe Prevention of the Primary Cesarean Delivery. Am J Obstet Gynecol. 2014; 210(3):179-93.

15. Macaulay S, Buchmann EJ, Dunger DB, Norris SA. Reliability and validity of last menstrual period for gestational age estimation in a low-to-middle-income setting. J Obstet Gynaecol Res. 2019; 45(1):217-25.

16. Gill JV, Boyle EM. Outcomes of infants born near term. Arch Dis Child. 2017; 102(2):194-8.

17. Mariani GL, Vain NE. The rising incidence and impact of non-medically indicated pre-labour cesarean section in Latin America. Semin Fetal Neonatal Med. 2019; 24(1):11-7.

18. Agência Nacional de Saúde Suplementar. Painel de indicadores de atenção materna e neonatal. [Accessed on: June $\left.28^{\text {th }}, 2020\right]$. Available at: http://www.ans.gov.br/ perfil-do-setor / dados-e-indicadores-do-setor/ painel-deindicadores-da-atencao-materna-e-neonatal.

19. Ministerio deSalud y DesarrolloSocial. Gráfico 9. Evolución de la Tasa de cesárea, porcentajes e intervalos de confianza del 95\%. Total, país. República Argentina. Años 2010-2018. En Sistema Informático Perinatal para la gestión (SIP-G). Indicadores básicos 2018. República Argentina. Buenos Aires: MINSAL; 2019:31. [Accessed on: June 28 ${ }^{\text {th }}, 2020$ ]. Available at: http:/ / www.msal.gob.ar/images/stories / bes/graficos / 0000001616cnt-anuario-sip-2018.pdf.

20. Organización Panamericana de la Salud. Sistema de Información Perinatal. [Accessed on: July $3^{\text {rd }}, 2020$ ]. Available at: https://www.paho.org/clap/index. php?option $=$ com_content\&view $=$ article $\& i d=84$ : sistemainformatico-perinatal\&Itemid $=242 \& l a n g=e n$.

21. Barber EL, Lundsberg L, Belanger K, Pettker CM, et al. Contributing indications to the rising cesarean delivery rate. Obstet Gynecol. 2011; 118(1):29-38.

22. Organización Mundial de la Salud. Solo se deben practicar las cesáreas que sean necesarias por motivos médicos. Comunicado de prensa. Abril 2015. [Accessed on: July $3^{\text {rd }}$, 2020]. Available at: https://www.who.int/mediacentre/ news/releases/2015/ caesarean-sections/es/.

23. Ceriani Cernadas JM. La epidemia de cesáreas no justificadas, ¿podremos revertirla? Arch Argent Pediatr. 2019; 117(2):66-7.

24. Sociedad de Obstetricia y Ginecología de Buenos Aires. Parto vaginal después de una cesárea. 2019. [Accessed on: July $\left.3^{\text {rd }}, 2020\right]$. Available at: http: / / sogiba.org.ar/images / Parto_Vaginal_despues_de_una_Cesarea_SOGIBA $\% 20$ 2019.pdf.

25. Fang YMV, Guirguis P, Borgida A, Feldman D, et al. Increased neonatal morbidity despite pulmonary maturity for deliveries occurring before 39 weeks. J Matern Fetal Neonatal Med. 2013; 26(1):79 $\square 8$.

26. Bates E, Rouse DJ, Mann ML, Chapman V, et al. Neonatal outcomes after demonstrated fetal lung maturity before 39 weeks of gestation. Obstet Gynecol. 2010; 116(6):1288 $\square 95$.

27. Ceriani Cernadas JM. Los cambios en la definición del recién nacido de término y su implicancia en los cuidados perinatales. ¿Se están cumpliendo? Arch Argent Pediatr. 2017; 115(5):410-1.

28. Martínez-Nadal S, Demestre X, Raspall F, Álvarez JA, et al. Morbilidad neonatal en los recién nacidos a término precoz. An Pediatr (Barc). 2014; 81(1):39 $\square 44$.

29. Goldenberg RL, Culhane JF, Iams JD, Romero R. Epidemiology and causes of preterm birth. Lancet. 2008; 371(9606):75-84.

30. Stewart DL, Barfield WD, COMMITTEE ON FETUS AND NEWBORN. Updates on an At-Risk Population: Late-Preterm and Early-Term Infants. Pediatrics. 2019; 144(5):e20192760.

31. Kugelman A, Colin AA. Late Preterm Infants: Near Term ButStill in a Critical Developmental Time Period. Pediatrics. 2013; 132(4):741-51.

32. Machado LCJr, Passini RJr, Rosa IR, CarvalhoHB. Neonatal outcomes of late preterm and early term birth. Eur J Obstet Gynecol Reprod Biol. 2014; 179:204 $\square$.

33. Pulver LS, Guest-Warnick G, Stoddard GJ, Byington CL, et al. Weight for gestational age affects the mortality of late preterm infants. Pediatrics. 2009; 123(6):e1072-7.

34. Wang ML, Dorer DJ, Fleming MP, Catlin EA. Clinical outcomes of near-term infants. Pediatrics. 2004;114(2):372-6.

35. Del Carmen GA, Stapleton S, Qadan M, Del Carmen MG, et al. Does the Day of the Week Predict a Cesarean Section? A Statewide Analysis. J Surg Res. 2020; 245:288-94.

36. Young D. When was the baby born? Reflecting on the time of day, day of week, mode of delivery, and birth outcomes. Birth. 2011; 38(1):1-2.

37. Nam JY, Lee SG, Nam CM, Park S, et al. The effect of offhour delivery on severe maternal morbidity: a populationbased cohort study. Eur J Public Health. 2019; 29(6):1031-6.

38. Pasupathy D, Wood AM, Pell JP, Fleming M, et al. Time of birth and risk of neonatal death at term: retrospective cohort study. BMJ. 2010; 341:c3498.

39. Brookfield KF, O'Malley K, El-Sayed YY, Blumenfeld YJ, et al. Does Time of Delivery Influence the Risk of Neonatal Morbidity? Am J Perinatol. 2016; 33(5):502-9.

40. MolaS, Graeber JE, Polak MJ, Yossuck P. Is friday the busiest for late preterm delivery? WV Med J. 2010; 106(5):10-3. 